\title{
Payment Strategies of Russian Consumers: Attitudes and Perceptions of Payment Instruments
}

\author{
Ekaterina Semerikova \\ Moscow School of Management SKOLKOVO
}

\begin{abstract}
Recently the landscape of the payment industry has changed significantly. Personal range of payment instruments and methods has become more extensive while consumer choice of which one to use for payment has become dependent not only on the socio-demographic factors but on their attitudes, perceptions and emotional response. The aim of this paper is to uncover payment strategies and explore perception of different payment instruments of Russian consumers. This study uses data of the qualitative research which included 4 stages: online diaries, secret agent, standard focus groups and mini-focus groups. The results show that three prioritized benefits determine which strategy a consumer chooses: speed, security or financial gain. The most trusted provider of payment services for Russian consumers is bank, while such banking payment products as debit cards is a new norm no matter the sociodemographic factors. This research aims at filling the gaps in the existing literature on payment consumer behavior at the emerging markets. The results might help financial institutions, especially banks, create products of better quality that solve consumer pain-points and develop strategies that consider behavioral peculiarities and preferences of Russian consumers.
\end{abstract}

Keywords: banking; behavior; cards; emerging market; financial innovation 